\title{
Melioidosis: Reporte de un caso en el departamento del Huila - Colombia
}

\author{
Melioidosis: A case report in the department of Huila - Colombia
}

Hugo Ernesto Osorio Carmona', Luis Fernando Durán²

\section{Resumen}

La Melioidosis es una enfermedad infecciosa ocasionada por Burkholderia pseudomallei, endémica en zonas tropicales de Asia y Australia, siendo una de las causas principales de neumonía y sepsis adquirida en la comunidad en algunas regiones de estos continentes. A nivel de América Latina se han reportado casos aislados autóctonos y otros importados, desconociéndose la epidemiologia de esta enfermedad. Reportamos el caso de un paciente de 72 años, diabético y con tabaquismo activo, que consulto por un cuadro febril de 10 días asociado a tos y síntomas inespecíficos, con evidencia imagenológica de neumonía, y aislamiento en hemocultivos de Burkholderia pseudomallei, sin mejoría clínica hasta recibir tratamiento antibiótico específico. Este caso se suma a otros reportes de procesos infecciosos ocasionados por esta bacteria en nuestro país, el cual cuenta con las condiciones climáticas ideales para su desarrollo.

Palabras clave: Melioidosis, Burkholderia pseudomallei.

\begin{abstract}
Melioidosis is an infectious disease caused by Burkholderia pseudomallei, endemicin tropical are as of Asia and Australia, being one of the leading causes of pneumonia and community-acquired sepsisin some regions of these continents. In Latin America there have been isolated, autochthonous reports and other imported, being epidemiology of this disease still unknown. Here it is reported the case of a 72 -year-old patient, active smoker with diabetes who had 10-day fever associated with cough and non specific symptoms, withX-rayevidence of pneumonia, and isolation in blood cultures of Burkholderia pseudomallei, without clinical improvement after receivings
\end{abstract}

pecific antibiotic treatment. This caseadds to other reports of infectious processes caused by this bacteriumin our country whose climatic conditions are ideal for their development.

Key words: Melioidosis, Burkholderia pseudomallei.

\section{Introducción}

La Melioidosis es una enfermedad tropical causada por un bacilo gram negativo, aerobio, móvil, oxidasa positivo, no esporulado, denominado Burkholderia pseudomallei, que afecta a humanos y animales, con una amplia variedad de manifestaciones clínicas no especificas, que incluyen estados asintomáticos, ulceras, abscesos en piel, procesos neumónicos crónicos, e incluso formas agudas con choque séptico y abscesos en múltiples órganos, con una mortalidad hasta del 40\%. ${ }^{[1,2]}$ La mayoría de casos son reportados en el sudeste de Asia y norte de Australia, ${ }^{[3,4]}$ donde es endémica, llegando a ser la principal causa de septicemia y neumonía comunitaria en Tailandia y algunas provincias de Australia, convirtiéndose en un problema de salud pública. ${ }^{2}$ Además se ha incluido como una de las enfermedades a tener en cuenta en viajeros que retornan de estas zonas, ${ }^{[5]}$ muchos de las cuales pueden mantenerse con la infección latente durante largos periodos de tiempo y luego reactivarse. En América se ha venido incrementando el reporte de casos esporádicos nativos ${ }^{[6-10]}$ y otros importados, ${ }^{[11,12]}$ considerándose como una enfermedad emergente, lo que genera el interrogante; de si el diagnóstico de esta entidad en nuestro continente y país ha sido subestimado. Los últimos reportes epidemiológicos catalogan a Colombia como un país con casos esporádicos, y posiblemente endémico. ${ }^{[2,13]}$

A continuación presentamos el caso clínico de un paciente que es remitido por un cuadro febril y síntomas inespecíficos sin mejoría con el manejo antibiótico empírico, hasta el aislamiento del microorganismo y tratamiento especifico.

1 Médico residente de tercer año de Medicina Interna, Universidad Surcolombiana, Hospital Universitario Hernando Moncaleano Perdomo de Neiva-Huila.

2 Médico internista de la Universidad Nacional, profesor de pregrado y posgrado de Medicina Interna, Universidad Surcolombiana. Hospital Universitario Hernando Moncaleano Perdomo de Neiva-Huila (Colombia).

Correspondencia: Hugo Emesto Osorio Carmona. Correo electrónico: hecosis16@yahoo.es

Recibido: 08/10/2013 - Revisado: 10/01/2014 - Aceptado: 21/09/2014 


\section{Caso clínico}

Paciente masculino de 72 años, procedente del corregimiento E1 Caguán, zona rural de Neiva - Huila, pensionado, dedicado a labores de jardinería en el hogar, con antecedente de tabaquismo activo, bebedor de alcohol ocasional, y diabetes mellitus tipo 2 desde hace 10 años, retinopatía diabética, en manejo con insulina NPH, metformina, ácido acetilsalicílico y atorvastatina.

Consulta a primer nivel por cuadro de 10 días de evolución de fiebre no cuantificada, asociado tos seca, astenia, adinamia, escalofríos, osteomialgias, mareo, diaforesis, cambios en el comportamiento, episodio de lipotimia, disuria y polaquiuria, por lo que inician antibiótico empírico para infección de vías urinarias con cefradina sin embargo el parcial de orina es no inflamatorio, por lo cual remiten al Hospital Universitario de Neiva

$\mathrm{Al}$ ingreso a urgencias, se encuentra en regular estado general, con mucosas secas, tensión arterial 120/80 mmHg, frecuencia cardíaca 112 por minuto, frecuencia respiratoria 16 por minuto, temperatura $36^{\circ} \mathrm{C}$, glucometria $152 \mathrm{mg} / \mathrm{dL}$, alerta, desorientado en tiempo y espacio, con ceguera izquierda y disminución de la agudeza visual derecha secundario a retinopatía diabética, sin signos meníngeos, el resto del examen físico es normal.
Se realiza tomografía de cráneo simple evidenciando infarto antiguo temporo-parietal derecho y cambios malacicos periventriculares extensos compatibles con enfermedad multi-infarto $\sin$ lesiones agudas, se realiza punción lumbar con citoquímico de líquido cefalorraquídeo normal. El parcial de orina, gram y urocultivo son negativos, BUN $23,2 \mathrm{mg} / \mathrm{dL}$, creatinina $1.43 \mathrm{mg} / \mathrm{dL}$, hemograma con 19.800 leucocitos, $89.8 \%$ neutrófilos, $6.2 \%$ linfocitos, HGB 13.5, VCM 90, CHCM 33 y plaquetas 199.000, radiografía de tórax con opacidades de ocupación alveolar, mal definidas, localizadas en el lóbulo superior y periferia del hemitórax izquierdo, considerándose neumonía adquirida en la comunidad e iniciando manejo antibiótico empírico con ampicilina/sulbactam $3 \mathrm{gr}$ endovenosos cada 6 horas. Durante las siguientes 72 horas persiste con picos febriles por lo que se adiciona claritromicina $500 \mathrm{mg}$ endovenosos cada 12 horas. Al quinto día se recibe reporte de hemocultivos 1 y 2 tomados al ingreso que reporta Burkholderia pseudomalle $i$ sensible a ceftazidima, imipenem, meropenem, y resistente a trimetoprim/sulfametoxazole (TMP/S). Se toma tomografía computada de alta resolución (TACAR) del tórax donde se objetiva consolidación en el segmento 3 del pulmón izquierdo, con broncograma aéreo, engrosamiento de las paredes bronquiales y tractos fibrosos (Figura 1), por lo que se suspende el esquema

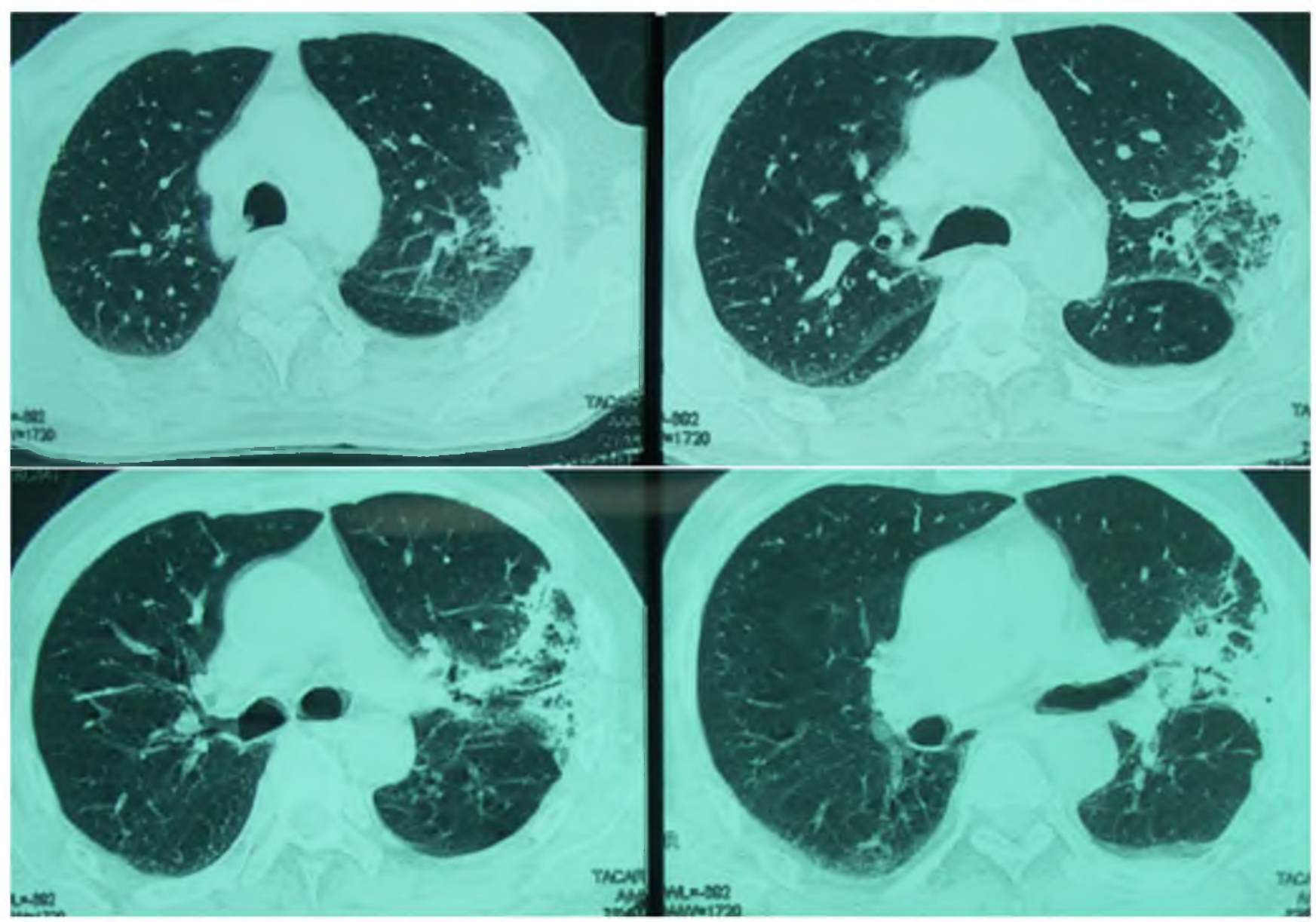

Figura 1. Enfisema subpleural difuso bilateral e imagen de consolidación en el segmento 3 del pulmón izquierdo, con broncograma aéreo, engrosamiento de las paredes bronquiales así como algunos trayectos fibróticos, esta lesión ocasiona discreta tracción craneal del hilio homolateral. 
antibiótico y se inicia meropenem 1 gramo endovenoso cada 8 horas durante 14 días. La evolución clínica fue favorable, sin presentar nuevos episodios de fiebre, con hemograma de control y proteína $\mathrm{C}$ reactiva normales.

$\mathrm{Al}$ completar el esquema antibiótico se toma TACAR de tórax de control encontrándose disminución en el volumen de la lesión intraparenquimatosa observada en el lóbulo superior del pulmón izquierdo, y se da alta médica para seguir manejo ambulatorio con TMP/S $160 / 800 \mathrm{mg}$ vía oral cada 12 horas y doxiciclina $100 \mathrm{mg}$ vía oral cada 12 horas por 3 meses, acido fólico, insulina, atorvastatina y acido acetilsalícilico, TACAR de tórax de control al mes del alta, con mejoría de los hallazgos imagenológicos iniciales (Figura 2) y resolución de los síntomas. El control médico a los 6 meses no evidencia signos o síntomas de reactivación de la enfermedad.

\section{Discusión}

Esta bacteria se aisla fácilmente en medios de cultivos estándar, donde puede ser confundida con $B$. cepacia y algunas especies de
Pseudomonas. Se encuentra presente en superficies del suelo y el agua en regiones endémicas, donde humanos y animales son infectados por inoculación percutánea, inhalación o ingestión, siendo la trasmisión persona a persona y zoonosis poco frecuentes. ${ }^{[1,3]} \mathrm{E} 1$ diagnóstico definitivo depende del aislamiento e identificación de la bacteria en medios de cultivo. Siendo difícil de realizar al momento de la presentación por lo inespecífico de las manifestaciones clínicas y la demora en el resultado de los cultivos ( 5 a 7 días)

Los factores de riesgo ambientales, se han relacionado con la exposición a campo abierto, sistemas de riego como en arrozales y granjas, suelos fangosos, donde hay gran humedad y el microorganismo es más comúnmente encontrado, siendo la inoculación percutánea e inhalación las principales vías de infección. ${ }^{[1,3]}$ Estos factores de riesgo están presentes en la mayoría de las zonas rurales de nuestro país, los cuales son similares a los observados en los países con alta endemicidad, como se evidenció en un estudio retrospectivo de serie de casos de Melioidosis realizado en AntioquiaColombia ${ }^{[8]}$ y un reporte de caso del Hospital Militar ${ }^{[9]}$ dejando la incertidumbre de si este microorganismo debe ser tenido en cuenta al momento de iniciar el manejo antibiótico empírico, cuando los fac-

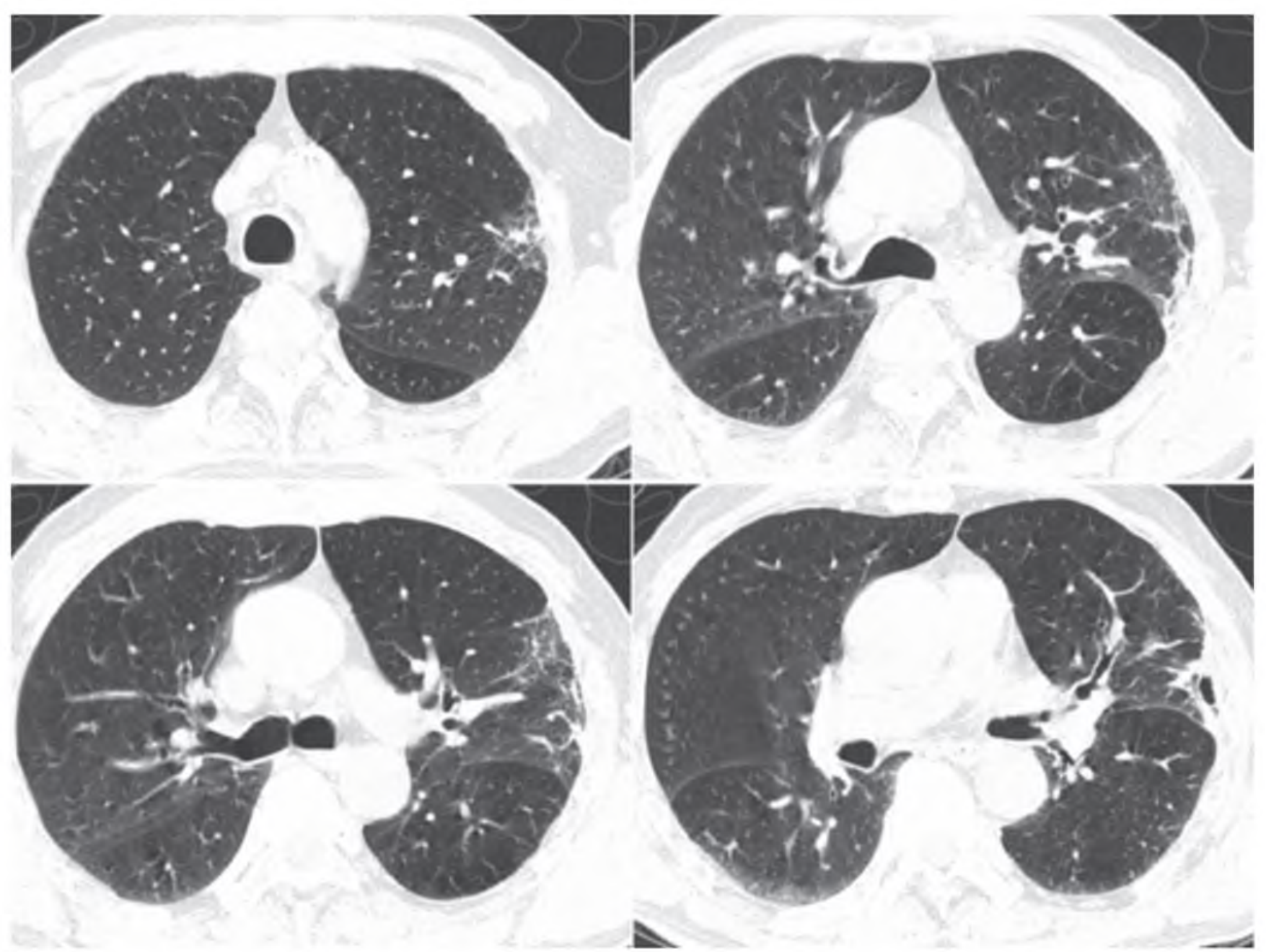

Figura 2. Análisis comparativo con el estudio inicial encontrándose disminución en el volumen de la lesión intraparenquimatosa observada en el lóbulo superior del pulmón izquierdo. 
tores de riesgo ambientales están presentes, y más en aquellos casos donde el proceso infeccioso no mejora con el esquema iniciado.

La presencia de estados mórbidos como la diabetes mellitus, enfermedad renal, cirrosis, neoplasias, enfermedad pulmonar obstructiva crónica, talasemia, uso crónico de corticoides y el alcoholismo, se han descrito como factores de riesgo para el desarrollo de infecciones severas como neumonía y septicemia, siendo el compromiso pulmonar una de las manifestaciones más frecuentes y asociada con mayor mortalidad. ${ }^{[2,3]}$

El período de incubación de la melioidosis y la severidad del cuadro son variables, y están determinadas por la dosis del inoculo, el modo de infección, factores de riesgo del huésped, y la virulencia de la cepa infectante. No se ha determinado que condiciones conllevan a la reactivación de la enfermedad en sujetos con infección latente, ni la duración del periodo de latencia, el cual se debe a la capacidad de la bacteria de vivir intracelularmente. ${ }^{[2,3]}$

Una de las causas del retraso en la identificación de este microorganismo (cinco días en nuestro caso), es lo inusual de su hallazgo en zonas donde no es endémico, lo que obliga a su confirmación mediante pruebas bioquímicas y enzimáticas. ${ }^{[14]}$ Todo esto prorroga la iniciación del tratamiento antibiótico especifico, teniendo en cuenta que a pesar de que $B$. pseudomalle $i$ es sensible a ceftazidima, TMP/S, carbapenémicos, amoxicilina/clavulanato y doxiciclina, presenta resistencia inherente a antibióticos muy utilizados como penicilina, ampicilina, cefalosporinas de primera y segunda generación, gentamicina, tobramicina, estreptomicina y polimixina, con poca actividad in vitro para ertapenem, moxifloxacino, y tigeciclina. ${ }^{[2]}$ El antibiótico con mayor evidencia en la fase aguda es la ceftazidima, sin embargo con meropenen e imipenem también se ha encontrado tasas de eficacia similares, ambos usados durante 14 días. ${ }^{[2,15]} \mathrm{En}$ zonas endémicas se recomienda que el manejo antibiótico empírico para neumonía comunitaria, incluya antibióticos con actividad contra B. pseudomallei, en aquellos pacientes que tienen factores de riesgo para Melioidosis. ${ }^{[2]}$

El tratamiento de erradicación más recomendado es la combinación de TMP/S y docixiclina ${ }^{[2,15]}$ con una duración de 3 a 6 meses, en nuestro caso usado durante tres meses, a pesar de que el antibiograma indicaba resistencia a TMP/S se decidió usar este antibiótico debido a la eficacia conocida en la eliminación de la bacteria, y a que el método de difusión sobreestima la resistencia. La adicción de ácido fólico es importante para disminuir la activad anti-folato del TMP/S. ${ }^{[15]}$ La adecuada adherencia es de vital importancia para asegurar la erradicación y evitar recaídas. La amoxicilina/ clavulanato es otra opción, pero presenta mayor tasa de recaídas. ${ }^{[2]}$

\section{Conclusión}

La Melioidosis es una enfermedad emergente en nuestro continente, con un creciente reporte de casos aislados en Colombia, país que cuenta con las condiciones ambientales propicias para el nicho ecológico de la bacteria. Sin embargo esta enfermedad es probable- mente sub-diagnosticada, por lo que se debe sospechar en aquellos pacientes que tienen factores de riesgo para su adquisición y desarrollo, más teniendo en cuenta el requerimiento de tratamiento antibiótico especifico para asegurar una terapia efectiva y evitar recaídas, debido a la resistencia inherente a los antibióticos frecuentemente usados de manera empírica.

\section{Referencias}

1. Mandell, Douglas, And Bennett's. Burkholderia pseudomallei and Burkholderia mallei: Melioidosis and Glanders. Principles and practice of infectious diseases. Ed. 7; 2010;221:2869-2879.

2. Wiersinga, W. Currie, B. Peacock, S. Melioidosis. N Engl J Med 2012;367:1035-1044.

3. Cheng AC, Currie BJ. Melioidosis: epidemiology, patophysiology, and management. Clin Microb Rev 2005; 18:383-416.

4. White NJ. Melioidosis. Lancet 2003;361:1715-1722.

5. Currie, B.J. Melioidosis: an important cause of pneumonia in residents of and travellers returned from endemic regions. Eur Respir J 2003;22:542-550.

6. Miralles IS, Maciel Mdo C, Angelo MR, et al. Burkholderia pseudomallei: a case report of a human infection in Ceará, Brazil. Rev Inst Med Trop Sao Paulo 2004;46:51-54.

7. Rolim DB, Sousa $A Q$, et al.Melioidosis, northeastern Brazil. Emerg Infect Dis 2005; 1 1:1458-1460.

8. Montufar F, Ochoa J, et al. Melioidosis in Colombia. An Emerging Disease. Chest. 2011;140:753A-753A.

9. González G, Mantilla W, Rada R. Neumonía y osteomielitis por burkholderia pseudomallei, reporte de un caso clínico. Rev Fad Med. 2009;17(1):146-149.

10. Inglis TJ, Rolim DB, Sousa AQ. Melioidosis in the Americas. Am J Trop Med Hyg 2006;75:947-954.

11. Messino A, Villegas I, Melioidosis en Costa Rica: reporte del primer caso. Acta méd. Costarric. San José set. $2000 ; 42(3)$.

12. Alzamurra $M$, Barreris $C$, ef al. Un caso de Melioidosis en la Argentina. MEDICINA (Buenos Aires) 2011;71: 39-41.

13. The global distribution of Burkholderia pseudomallei and melioidosis: an update. Trans R Soc Trop Med Hyg 2008; 102(Suppl 1):S1-S4

14. Inglis TJ, Merritt A, Chidlow G, Aravena-Roman M, Harnett $G$. Comparison of diagnostic laboratory methods for identification of Burkholderia pseudomallei. J Clin Microbiol. 2005;43:2201-2206.

15. Allen C. Cheng. Melioidosis: advances in diagnosis and treatment. Current Opinion in Infectious Diseases 2010;23:554-559. 